\title{
LA LÍRICA SANTIAGUERA EN LA ETAPA REPUBLICANA $(1902-1923)$
}

\author{
Ronald Antonio Ramírez Castellanos \\ Departamento de Letras, Facultad de Humanidades \\ Universidad de Oriente, Cuba. \\ ronald@uo.edu.cu; ronaldinhosoyyo@gmail.com
}

\section{RESUMEN / ABSTRACT}

El estudio del patrimonio literario en Santiago de Cuba en la etapa republicana ofrece zonas de interés a las actuales investigaciones que se realizan en instituciones académicas y culturales del territorio. Obras, autores y géneros de la literatura como expresión cultural de esta ciudad no han sido lo suficientemente justipreciados por la historiografía y la crítica literaria nacionales. El género lírico merece mayor atención debido a la vasta tradición poética que Santiago de Cuba ha sedimentado a lo largo de los años. Es por ello que, en el presente trabajo, a través de una búsqueda bibliográfica minuciosa y mediante la aplicación del análisis de contenido como método, se dilucidan aspectos de interés que permiten determinar cuáles fueron los autores, sus textos y las diferentes manifestaciones ideoestéticas del género poético, cuyas aportaciones resultan medulares para el necesario ejercicio de reescritura de la historia literaria santiaguera en la etapa comprendida entre 1902-1923.

Palabras clave: lírica, Santiago de Cuba, etapa republicana, romanticismo, postmodernismo.

The study of the literary heritage in Santiago de Cuba in the Republican stage offers areas of interest to current research being conducted in academic and cultural institutions of the territory. Works, authors and genres that comprise the literature as a cultural expression of this city has not yet been sufficiently appraised valued by historiography and national literary criticism. The lyric, in particular, as it is known the vast poetic tradition that Santiago de Cuba has settled over the years. That is why, in this paper, through a thorough literature search and by applying content analysis, aspects of interest which can identify the authors, texts and different ideo-esthetics manifestations of the poetic genre were elucidated, whose contributions are core to the necessary exercise of Santiago rewriting literary history in the period between 1902-1923.

KEYWORDS: lyrical, Santiago de Cuba, Republican period, romanticism, postmodernism. 


\section{INTRODUCCIÓN}

En 1898, Santiago de Cuba era una ciudad devastada por la guerra. El conflicto bélico que decidió el cese del poderío colonial español en la isla de Cuba, la contienda hispano-cubano-norteamericana, había tenido como escenario fundamental a la capital oriental del país y, desde aquí, se dio inicio a la ocupación militar estadounidense del territorio insular hasta el establecimiento, el 20 de mayo de 1902, de una república supeditada a los designios de Washington en el orden político, social y económico. En el aspecto cultural, el panorama que ofrecía la cuna de notables poetas de la centuria decimonónica como José María Heredia, Luisa Pérez de Zambrana, Pedro Santacilia, por solo mencionar algunos, era, con mucho, desolador.

Si bien a partir de la década del 80 del siglo XIX Santiago de Cuba había experimentado un revitalizado auge de la actividad intelectual, sobre todo con la aparición de diversas publicaciones culturales que circularon hasta 1894, el último estallido insurreccional independentista limitó significativamente el ambiente artístico-literario, debido a la incorporación de gran parte del sector progresista santiaguero a las labores conspirativas, tanto en los campos orientales como en el exilio. A lo anterior se añade la clausura de toda actividad cultural, vista como tendencia separatista por la férrea censura española. Hay, ciertamente, una parálisis marcada por los trascendentales acontecimientos políticos de la etapa, la cual frenó el desarrollo del movimiento literario regional y, en particular, del género poético, de vasta tradición entre los escritores santiagueros. La estética romántica, de amplio predominio en las composiciones líricas publicadas durante el período decimonónico, estaba a la orden del día.

No obstante, con la entrada del nuevo siglo XX, se aprecia una creciente recuperación del hecho poético en la región que, a diferencia de la etapa precedente, no ha sido lo suficientemente documentada por los estudiosos de la literatura nacional y regional. Es perceptible en los más recientes manuales historiográficos que se adentran en el estudio de los géneros literarios, y en especial de la lírica, un vacío epistemológico, la ausencia notable de referencias a autores y obras que, hoy día, resultan desconocidos para la más actual generación de investigadores, académicos y estudiantes en general de la literatura cubana. De este modo, el presente artículo tiene como objetivo determinar las coordenadas de las diferentes manifestaciones ideoestéticas de la lírica santiaguera en el lapso comprendido entre 19021923, empleando como método de trabajo la investigación bibliográfica 
y el análisis de contenido. Con ello, se dilucidan los autores y obras más significativos para el recuento imprescindible de la historia de la poesía en Santiago de Cuba en la etapa republicana. El rescate y preservación de este registro importante de los principales exponentes del patrimonio lírico de dicha ciudad constituye el aporte medular de la presente investigación. Es, al mismo tiempo, una respuesta a las necesidades de potenciar, desde las ciencias literarias, la salvaguarda del legado artístico y literario de la ciudad de Santiago de Cuba, en la memoria colectiva de la patrilocalidad.

\section{TRADICIÓN Y TRANSICIÓN: EL OCASO DEL ROMANTICISMO DECIMONÓNICO}

Con la instauración de la república fueron creándose paulatinamente las condiciones para retomar las labores culturales e intelectuales en el escenario regional santiaguero, cuyo despegue definitivo puede ubicarse a partir de 1904, debido a dos acontecimientos de vital relevancia: el primero, la llegada a la ciudad -en calidad de emigrantes-, de notorios miembros de la familia dominicana Henríquez Ureña, entre ellos, Maximiliano, por entonces un joven tempranamente convertido en incansable promotor de la intelectualidad citadina santiaguera durante las tres décadas iniciales de la etapa republicana. El segundo acontecimiento lo constituye la aparición de la revista Cuba Literaria, fundada por Max Henríquez. Esta publicación se convirtió en órgano difusor del movimiento cultural oriental que, como ninguna otra de su tipo en estos años, alcanzó ecos significativos en la capital de la Isla y en otras regiones de Iberoamérica.

Cuando se realice un recuento crítico e historiográfico de la literatura en Santiago de Cuba, el fenómeno Cuba Literaria no puede entenderse como un mero pasatiempo cultural gestado por un intelectual foráneo, cuya primera estadía en nuestra ciudad apenas rebasó poco más de un año. La ciudad cabecera oriental, asidero de una rica trayectoria artística desde la segunda mitad del XIX, ya había comenzado a dar señales de relativa recuperación desde 1902, con la aparición regular de escasas publicaciones de corte literario. En ellos se dio a conocer una nueva promoción de autores locales que más tarde consolidarían un significativo prestigio en el escenario cultural de la ciudad. Recién llegado de Santo Domingo, Max Henríquez Ureña (1885-1968) supo captar este espíritu de efervescencia intelectual que se respiraba. Las 
páginas de Cuba Literaria sirvieron de vehículo al desarrollo de los géneros más representativos cultivados por estos escritores, en particular, de la poesía.

Rafael Pullés y Palacios (1858-1917), Daniel Bertrán Maroto, Pierrot (1869-?) ${ }^{1}$, Horacio V. Febles, el habanero-santiaguero Ginés Escanaverino de Linares (1834-1906), Joaquín Navarro Riera, Ducazcal (1872-1950), Manuel Pérez Silva, junto a integrantes de la colonia dominicana en Santiago de Cuba, como Temístocles Ravelo (1854-1936), Manuel de Jesús de Peña y Reinoso (1833-1915), José Marino Henríquez y el propio Max Henríquez Ureña fueron algunos de los autores que con más frecuencia enviaron sus colaboraciones poéticas a la revista. En sus páginas, los temas característicos abordados -la mujer amada, los amores frustrados, la patria, las recién finalizadas luchas independentistas y sus héroes en tanto símbolos nacionales-conformaron un tipo de poesía amoroso-intimista y de corte histórico, marcado por la estética del romanticismo epigonal.

Los ecos del triunfo del santiaguero Enrique Hernández Miyares (18591914), radicado en La Habana, a propósito de su poema "La más fermosa" (probablemente el soneto más célebre en la historia de la literatura cubana), fueron también difundidos en Cuba Literaria. Aunque casi toda la producción poética de este escritor había sido escrita lejos del ámbito oriental, esta merece la atención de la crítica como ejemplo de composiciones románticas resistentes al influjo modernista, las cuales apostaban, en algunos casos, por una reafirmación del nacionalismo patriótico ante la creciente injerencia norteamericana en la esfera política del país ${ }^{2}$.

Aun cuando a través de las páginas de Cuba Literaria Max Henríquez Ureña realizara notables esfuerzos por divulgar el espíritu modernista en las

\footnotetext{
En las menciones a los escritores santiagueros aquí analizados se ha tratado de ser lo más preciso posible en la consignación de sus fechas de nacimiento y muerte, datos que se toman del Diccionario de Literatura Cubana (1980-1984) y de León Estrada (2013). El signo de interrogación indica que algunos de estos datos no se conocen en los registros efectuados por la historiografía literaria nacional y regional. Cuando no esté ni uno ni otro, solo aparecerá el nombre completo.

En su poema "Dos banderas", por ejemplo, es evidente la influencia del clásico poema de Bonifacio Byrne ("Mi bandera") y el ya citado "La más fermosa" se inspira en un memorable discurso de Manuel Sanguily ante el Congreso de la República en el cual manifestó abiertamente su postura contraria a la firma del Tratado de Reciprocidad Comercial con los Estados Unidos.
} 
voces de sus más legítimos exponentes ${ }^{3}$, ello no fue impedimento para que el ejercicio continuado de la tradición romántica en la poesía prevaleciera en la praxis escritural de la generación finisecular decimonónica y en la de la primera promoción de escritores republicanos. No obstante, son apreciables en algunas de las composiciones de Pullés y Palacios, por ejemplo, atisbos de la tendencia renovadora ("Guayo", "Doble cautiverio"), a pesar de que, en sentido general, su obra lírica, rescatada en parte recientemente ${ }^{4}$, evidencia la filiación romántica de su autor. El propio Max Henríquez Ureña, cuyos aportes fundamentales a nuestra historiografía literaria se concentrarán, en lo adelante, en sus trabajos ensayísticos, intentará, sin relieve significativo, adscribirse a las reminiscencias darianas. En este sentido, sus poemas de juventud en Cuba Literaria ("Visión", "Madrigal”, "Aquelarre", "A solas"), su posterior Ánforas (1914), que publica fuera del contexto santiaguero y Fosforescencias (1930), de tardío postmodernismo, son muestras palpables que aseveran la anterior afirmación.

La partida súbita de Henríquez Ureña para la capital del país en 1905 y su salida posterior a México en ese mismo año, impidió la continuidad de la más importante publicación santiaguera de este lapso ${ }^{5}$. Sin embargo, no faltaron a nuestros escritores locales otras vías expeditas para materializar la edición de sus textos poéticos, casi siempre en las páginas culturales de las revistas del período, entre las cuales las más significativas fueron, en este orden: Ilustración Cubana (1906-1907); Revista de Santiago (1907), El Pensil (1907-1910), Renacimiento (1910-1911) y Oriente Literario (19101913). A los autores ya mencionados debe añadírsele otra compacta lista: Miguel Ángel Escanaverino, Santiago Fals (1857[1859]-?), José Iglesias Infante (1886-1967), José G. Pujals, José García Rodríguez, Manuel Mateo, las poetisas Elvira Valbuena de Moro (1851-?) y Caridad Tintoré Ramos (1882-?), quienes, si bien no aportaron composiciones poéticas de calidad

\footnotetext{
Se publicaron textos de Darío y Casal, a quienes se les dedicó números especiales de la revista; de los hermanos Federico y Carlos Uhrbach, así como de las más recientes producciones poéticas de autores de la capital, más atentos a las nuevas tendencias ideoestéticas en la lírica que los del Oriente del país, por razones de favorecimiento cultural y geográfico.

Canseco Aparicio, Margarita et al., Nocturnal. Poesía escogida de Rafael Pullés y Palacios. Santiago de Cuba: Ediciones Santiago, 2010.

A juicio del autor de este artículo, no será superada en calidad estética hasta 1928, con la salida de Archipiélago, órgano de la filial Hispano-Cubano de Cultura en Oriente, también fundada por Max Henríquez Ureña.
} 
artística notable en los años iniciales del siglo XX, su impronta responde a los postulados ideoestéticos de la lírica santiaguera, incólumes hasta la segunda década de la etapa: por una parte, una poesía intimista romántica, partícipe de temas amorosos y rasgos autobiográficos, con formas y estilos en desuso, legados de la tradición decimonónica; por otra, una poesía de carácter histórico, de acentuado matiz identitario con referencia a las gestas independentistas y sus próceres (Antonio Maceo, en primer lugar, y José Martí después), representantes de los más genuinos símbolos de lucha e idiosincrasia nacionales.

En saldos generales, la primera década republicana en Santiago de Cuba no registra un ejercicio poético que resalte por su calidad artística, mayoritariamente desarrollado en páginas de publicaciones periódicas de espectros diversos (masónicos, médicos, deportivos, gremiales, etc.). Hasta donde fue posible indagar, solo se publicaron dos poemarios: Pórfidos (1906), de Antonio Poveda Ferrer (1858-1945) y Ensayos poéticos (1907), de Caridad Tintoré (Estrada 113), ejemplares que no se han podido localizar hasta el presente. Esta consustancial carencia de libros poéticos se debe, en gran medida, a la precaria situación económica de los escritores locales, imposibilitados de pagar los costos de edición de sus obras. Ciertamente, las colaboraciones que hicieron a las planas culturales de revistas y periódicos de estos años resultaban modos mucho más rápidos y eficaces para darse a conocer ante el público lector, al mismo tiempo que no constituían gastos financieros para sus desvalidos ingresos. Sin embargo, a pesar de estas dificultades y del discreto ejercicio poético en la década, antes que de un estancamiento, como aconteció en el espectro lírico insular, lo más acertado sería hablar-coincido con el criterio de López Lemus (19)- de un agonizante, pero inevitable período de transición de las estéticas compositivas del género en el ámbito literario santiaguero, que ya para el período de 1910 a 1923 alcanzaría un renovado auge.

\section{POSTMODERNISMO Y NEORROMANTICISMO: ESTÉTICAS CONVERGENTES}

Este desarrollo ulterior, precisamente, encontrará su caldo de cultivo en dos hechos fundamentales que en el último lustro de la década inicial estaban en franco proceso de fermentación: en primer lugar, el surgimiento de la generación abanderada de poetas santiagueros a partir de 1910, que desde tres 
años antes avizoraban adueñarse de lugares cimeros en el parnaso poético de la ciudad. Sus textos, aún de añeja expresión romántica y todavía resistente a las concepciones decadentistas y modernistas, serían reproducidos en revistas culturales como El Pensil, Renacimiento, Oriente Literario, difusoras de la llamada renovación postmodernista en el género. Aquí se incluye a los tres Povedas: Luis Aguiar (1899-1976?), Héctor Arístides (1890-1968) y José Manuel (1888-1926); Fernando Torralva (1885-1913), el colombiano Pascual Guerrero (1894-1946) y Luis Vázquez de Cuberos (1889-1924), quienes junto a Enrique Gay Calbó (1889-1977), Juan Jérez Villarreal (1892[1899-1890?]-?), el dominicano Arístides Sócrates Nolasco (1884-1980), y otros, integrarían el Grupo conocido como "Cenáculo", impulsores de la estética modernista inspirada en el legado lírico casaliano y del nicaragüense Rubén Darío. En segundo lugar, la formación de un núcleo de poetas que consolidará la tendencia neorromántica en todo el ámbito literario santiaguero. Estos autores, si bien en algunos casos no pudieron sustraerse a las nuevas concepciones de expresión del hecho lírico, en sentido general optaron por la continuidad de la estética decimonónica al uso, inspirados en el legado de sus predecesores Heredia, Plácido, Avellaneda y Luisa Pérez de Zambrana y en el de los clásicos del romanticismo español, perpetuando temas y formas composicionales y estilísticas, en las que el placer sonetista estuvo a la orden del día. En este grupo puede citarse a Daniel Bertrán, Pedro Duany Méndez (1891-1952), Arturo Clavijo Tisseur (1886-1958), Arturo de Lastre Manduley (1892-1958), Joaquín Navarro Riera, Pedro Yodú Griñán, entre otros.

De esta manera, tanto el postmodernismo como el neorromanticismo en la poesía santiaguera republicana determinaron la conformación de un corpus nutrido de heterogéneas fuentes, pero principalmente de savia popular, con matices identitarios fortalecedores de la conciencia nacional y del sentido idiosincrático de los valores locales autóctonos, exaltados en textos poéticos de relativa trascendencia. Algunos con significativas resonancias más allá de las fronteras regionales; otros, en muchos aspectos, ciertamente permeados de un romanticismo extemporáneo, teñido de típica e insustancial cursilería, mal vista por la crítica de la época y posterior. Fueron obras catalogadas de escasa o irrelevante factura, juicio que si bien atiende a razones de índole estética, no puede sostenerse sin el análisis crítico y justo, desprejuiciado de gustos y modos individuales (exclusivistas per se), al margen de la necesaria contextualización de autores, obras y tendencias.

Si los diez primeros años de alborada republicana evidencian un proceso de prolongado ejercicio romántico en la lírica santiaguera, a partir de 1913 
se refleja un denodado equilibrio entre lo tradicional y las nuevas prácticas renovadoras postmodernistas, circunscritas en el plano composicional al empleo del versolibrismo. Aun cuando el empleo del soneto con un extemporáneo aliento romántico no fue abandonado del todo, otros tópicos como las alusiones a los conflictos existenciales del hombre, la exaltación del yo poético abrumado por el hastío, la soledad y el desamparo, ensayaron concepciones más complejas de elaboración del hecho lírico en gran parte de las obras aquí referenciadas.

Junto a la labor de promoción de los nuevos valores literarios, desempeñada por las revistas anteriormente citadas, debe destacarse la importancia que tuvo para el desarrollo no solo del género lírico en particular, sino de toda la literatura santiaguera del período, la página cultural dominical de El Cubano Libre, uno de los rotativos de mayor circulación en la época en la capital oriental del país. Esta página, surgida en 1910, duraría hasta 1926, descontando algunas interrupciones determinadas por acontecimientos políticos en la región que limitaron la salida del periódico, primero con el título de "Domingos de El Cubano Libre", luego con el de "Sabatina Literaria", cuando ya el rotativo había restringido su salida diaria hasta los sábados. Con uno u otro nombre, esta página constituyó un fenómeno cultural de invaluables aportes histórico-literarios que, hasta el presente, lamentablemente, no ha merecido la atención y el análisis que debiera por parte de la crítica y la historiografía literaria local y nacional. Dirigida en sus inicios por Joaquín Navarro Riera, la página "Domingos de El Cubano Libre" no solo aglutinó, en sus sucesivas ediciones, a un nutrido grupo de escritores de la ciudad; también apostó por la divulgación de textos de colaboradores nacionales y extranjeros en los diferentes géneros literarios.

Aunque no es propósito ofrecer en este artículo una pormenorización exhaustiva de los aportes del mencionado suplemento cultural a la literatura santiaguera, es necesario subrayar su desempeño como vehículo y difusor del polémico debate entre neorrománticos y postmodernistas, exégesis en pugna durante la segunda década republicana. Navarro Riera, heredero de la tradición decimonónica epigonal, defendía la estética que, desde su punto de vista, resultaba procedente para el fomento de la práctica poética. Detractor de la "peste postmodernista" enarbolada por herejes y escritorzuelos sin cultura, según sus propias palabras (10), apostaba por el mantenimiento de la tradición clásica en formas, estilos y temas que el diecinueve había radicalizado en el género lírico insular. Aun cuando fue esta su posición durante los inicios, no es cierto que tales razonamientos ni postura colocaron 
un freno a las nuevas pretensiones transformadoras del "Cenáculo", gestadas en las enconadas reuniones y debates promovidos por el genio intelectual de José Manuel Poveda.

Hombre culto, modesto y de reconocido prestigio entre sus contemporáneos, Ducazcal prontamente comprendió la imposibilidad de sustraerse a las nuevas tendencias de expresionismo lírico, por lo que a partir de 1912 ya es palpable una apertura en los "Domingos de El Cubano Libre" a los textos de los más relevantes miembros del Grupo del Palo Hueco, aunque todavía lastrados por un romanticismo epigonal. Partidario de una posición neutral, Navarro Riera no ofreció reparos a la publicación en el suplemento literario de las acérrimas y enconadas críticas povedeanas a la pléyade "cursi y pseudoliteraria" encabezada por Daniel Bertrán, Miguel Ángel Escanaverino, Clavijo Tisseur y otros tantos, ni a la infructífera campaña del autor de Versos Precursores que pretendió boicotear la celebración de los Juegos Florales a la que por estos años convocó la Asociación de la Prensa en Oriente. Ducazcal acogió la crítica de Poveda contra el flujo migratorio de vates foráneos que, desde finales de 1906 y hasta 1914, se incorporaron al efervescente mundillo poético que afloraba en la ciudad.

Los textos de los españoles Joaquín Aristigueta Sanromán Iokonan (1888-1973) y José Manuel Campoamor (1892-1961), del italiano Nicola D’Angelo, del desconocido bohemio Ismael Vázquez Yépez, entre otros, acogidos en las páginas literarias desde Ilustración Cubana hasta Oriente Literario y propiamente en los "Domingos...", como testimonio de su presencia en Santiago de Cuba por estos años, serán blanco de la crítica povedeana pues, a su juicio, constituían ejemplos publicísticos de la "plaga pseudoliteraria" expandida en los círculos literarios locales. Solo escaparán a tales consideraciones Max Henríquez Ureña - ausente de la ciudad y figura respetada-, Sócrates Nolasco, miembro activísimo y fundador del Cenáculo oriental, así como el colombiano Pascual Guerrero, al decir de Ducazcal, un "pobre ruiseñor aprisionado en estrecha jaula" (10), que tras vegetar en el mostrador de una tabaquería santiaguera para ganarse el pan, obtuvo la jefatura de redacción de la revista Oriente y Bohemia (1910).

A la pluma de Guerrero se debe uno de los primeros poemarios publicados en la segunda década del XX, Almas ausentes (1912), y al que le seguirán otros dos, de considerable factura: Voces del silencio (1915) -con prólogo de Maximiliano Henríquez-y Ritmos panteístas (1918). En estos textos se evidencia el equilibrio entre tradición neorromántica y postmodernismo, bifurcaciones del género lírico en la etapa, manidas, indistintamente, por la 
inmensa galería de vates orientales. Llama poderosamente la atención que las composiciones líricas incluidas por Guerrero en cada uno de sus libros, habían sido dadas a conocer con anterioridad en las páginas de los "Domingos de El Cubano Libre". Esta estrategia también será asumida, en lo sucesivo, por Santiago Fals, Clavijo Tisseur, Aristigueta, Enrique Cazade (1891-?) el propio Poveda, quienes, sacrificio mediante, conseguirán pagar los costos de edición exigidos por las casas publicísticas de la ciudad y la región ${ }^{6}$.

En Almas ausentes, la estética de Guerrero transita desde la reflexión filosófica en poemas que cuestionan el existencialismo humano, con notas de amargura y pesimismo ("Exhortación", "Sin luz", "Lira enferma"), a la poesía amoroso-intimista con fugaces destellos eróticos. El sujeto lírico, asido por la soledad y la añoranza, transparenta su amargura por la ausencia de la mujer amada ("De mi romanticismo"). La agonía ante la cotidianeidad vulgar, asfixiante y monótona de la vida en provincias ("Cuadros provinciales"); la evocación del emigrante infeliz que sueña y anhela la lejana patria que ha quedado atrás ("Único amor") son otras de las características de los textos poéticos de Guerrero. Max Henríquez Ureña califica este poemario como un libro de adolescencia. Sin embargo, la mejor obra de Guerrero, En silencio (1918), ya vislumbra el cuidado de la forma y la homogeneidad temática en pintorescos cuadros simbolistas, reveladores, en su trasfondo, de la esencia povedeana. El silencio retroalimenta su espíritu que divaga obsesionado en la búsqueda de las respuestas a los dilemas de la existencia humana. Sufrimiento, amargura, frustración, muerte-vida, noche-silencio: he aquí las concatenaciones laberínticas en las que el sujeto lírico disemina su agonía en un haz de oposiciones binarias; cuestionamientos inescrutables que no conseguirán revelar nunca la incógnita del aquí-ahora y del allá metafísico, perpetua ofuscación en la exégesis modernista de nuestros escritores locales. Es una voz amordazada por el silencio y la carencia que se refugia una y otra vez en la noche, a la que intenta arrebatarle vanamente sus misterios. Y en ella se debate en tanto atisba, errático, destellos de aurora.

\footnotetext{
Algunos, como Clavijo Tisseur, acudirán a la ayuda de benefactores con mayor solvencia económica (Ravelo, Bacardí, Bernardo Callejas, el español Francisco Villaespesa), a los cuales se les enviaba un ejemplar del texto con la solicitud de contribuir, en la medida de sus posibilidades, con un óbolo generoso, al pago de los costos de la edición. Esta forma podía ser vista, tanto por ellos como por sus contemporáneos, como un apadrinamiento y contribución, por modesta que fuese, al desarrollo de la literatura en la localidad y tal vez, al éxito de un futuro intelectual de renombre.
} 
En silencio ya se divisa lo que Bernardo G. Barros (11) advertirá en el tercer poemario de Pascual Guerrero: la estética de los contrastes, el recurso del claroscuro. Vida-muerte, noche-aurora: maniqueísmo lírico ausente de todo equilibrio; dolor, martirio, incertidumbre, tristeza, es el poeta predestinado al fatalismo del que no puede escapar, pues para él la vida ("noche que nos sumerge en el letargo, // condena de dolores transitorios, // flor que muere al nacer, y sin embargo // la miramos con ojos ilusorios. // ¡Oh, tesoro fatal!”) es efímera. Por ello, Pascual Guerrero agoniza. Y como Fernando Torralva, Luis Vázquez de Cuberos y José Manuel Poveda, las voces líricas del parnaso santiaguero más expresivas del postmodernismo, morirá temprano. Hay un hálito casaliano, una especie de maldición profética que asfixia y condena a estos interesantes precursores del género al fatalismo, a la frustración, al desequilibrio psicológico y a la miseria en unos más que en otros. Es una suerte de calvario que pesarosamente estos poetas aceptan indiferentes, bucólicos, románticos, pues nacieron para sufrir, inadaptados, la sádica agonía de la vida.

Fernando Torralva fue, de todos, quizás el más atormentado. Espíritu romántico por naturaleza-se dice que marcado por las penurias y las escaseces materiales desde niño-, creció, no obstante, motivado por una insaciable sed de cultura. El autodidactismo fue su escuela, como la de muchos de los poetas locales. Delicado, refinado, culto, puede decirse que Torralva, sensible a la belleza femenina, enarboló como pocos el estandarte de la poesía amorosa, lo que le valió en diversas ocasiones el triunfo en algunos certámenes poéticos citadinos. No obstante, la irresistible savia povedeana, presente en las composiciones publicadas a partir de 1910, tanto en "Los Domingos de El Cubano Libre" como en Oriente Literario (de la cual fue uno de sus directores), perfiló la nueva orientación de su estro poético, trunco cuando ya advertirá señales de madurez con la aparición de lo que, a juicio del investigador, constituye su mejor composición lograda: "La canción del viador", el canto que abofeteó la vida (Poveda 205), de hálito amargo, lúgubre, fatalista, como su espíritu todo, inquieto, nervioso, apasionante, atormentado. Este poema puede considerarse un texto profético, anunciador del trágico suicidio de Torralva que escandalizará los círculos intelectuales de la ciudad santiaguera el 19 de octubre de 1913. Existen referencias sobre la publicación (¿póstuma?) de sus composiciones, pero se ignora si en ese volumen desaparecido se halla definitivamente su poesía completa. De no ser así, es lamentable que todavía permanezca dispersa en las revistas en las cuales colaboró y en las páginas de los "Domingos...", pues en ellas se percibe una fabulosa ejecutoria poética que hubiera constituido un hito en el panorama lírico insular, de no haberse malogrado en aquella tragedia estremecedora. 
Por otra parte, Luis Vázquez de Cuberos moriría enfermo, tuberculoso y agobiado por la miseria en la capital. Había decidido huir tempranamente del provincianismo vulgar del Santiago republicano de las primeras décadas, para probar en La Habana mejor fortuna. Pocos años antes, ya era poeta reconocido en las publicaciones culturales, por lo que sus composiciones líricas, aparecidas en forma de libro en 1922, corresponden, en verdad, a la década anterior. Las influencias parnasianas en sus textos, aún de perceptibles reminiscencias románticas, hacen de su discurso el menos relevante de nuestros postmodernistas. No obstante, hallamos en "La pampa", el poema que le mereciera el mayor reconocimiento entre sus contemporáneos, algunos intersticios de poesía social, de proyección ideológica latinoamericanista.

Sin dudas, José Manuel Poveda y Calderín, el más trascendental de los poetas santiagueros de la renovación modernista y de todo el período republicano, ha sido el único que ha merecido el estudio y el justo reconocimiento por parte de la historiografía y la crítica literaria nacionales. Polémico, versátil, vigoroso, controvertido, enarboló los estandartes de la renovación, inspirado en el legado de Julián del Casal y de los parnasianos y simbolistas franceses. Sus textos poéticos incluidos en su monumental y único libro publicado en vida, Versos precursores (1917) representa, con razón, el volumen que define el panorama de la lírica insular de la etapa. No es necesario profundizar aquí en las particularidades de su impronta estética, pues sus más encomiables estudiosos, encabezados por el crítico Alberto Rocasolano, se han encargado de precisar, en todos sus detalles, los aportes de este clásico poemario (1975).

En líneas generales, el texto es síntesis de la actitud escéptica y del pesimismo fatalista de un hombre que no supo adaptarse a las circunstancias sociopolíticas y culturales de una república lacerada por el espíritu de frustración nacional. Su estética, expresión de una organicidad ideotemática integrada desde la más hermética individualidad, denota el conflicto ontológico del poeta agobiado por el hastío y la incertidumbre. Su experiencia personal de vida, estructura la arquitectura modernista de sus versos marcados por el cerebralismo y su preocupación más recurrente: la conciencia tanática. Amor, muerte, el destino, la relación antagónica del bien y el mal, la vida, el orgullo, el erotismo, exégesis temática de sus textos líricos ${ }^{7}$, revelan la complejidad del estro poético povedeano. Bastó un solo texto para que su autor 
se consagrara como un poeta de élite, de minoría. Sin embargo, ello no fue debidamente justipreciado por sus contemporáneos locales quienes hicieron lo posible por desterrar de los predios intelectuales de la indómita ciudad la pléyade modernista y a su "excéntrico" promotor; escasos comentarios positivos recibió durante su eximia vida. Tardaría mucho tiempo -muerto ya José Manuel Poveda-para que la crítica insular emprendiera, de manera paulatina, las primeras reivindicaciones en torno a su emblemática figura y legado. Pero 1917 no debe verse solamente como un año cristalizador de la praxis renovadora en la lírica escrita por autores santiagueros sino también como la fecha en que el neorromanticismo poético regional tendrá, con la aparición de Albores y penumbras, el primer libro de Arturo Clavijo Tisseur, a su exponente más representativo.

Escritor de formación autodidacta, barbero de profesión, Clavijo Tisseur desarrolla una extensa obra en los géneros poético, narrativo y dramático, así como la escritura de ensayos históricos y de crítica literaria. Con sus artículos periodísticos colaboró, desde fechas tempranas, en la prensa y revistas culturales de la región oriental y del resto del país. Albores y Penumbras define, desde este propio inicio, las características de lo que será toda la producción lírica clavijiana. El libro resalta por su marcado sentir neorromántico: poesías de rasgos marcadamente autobiográficos dentro de la vertiente amorosa-intimista ("Así es mi gitanilla", "A Fela", "Días de gloria", "Mis flores", "Canto a Guantánamo", "Ruegos"). En los poemas de temática histórica exterioriza su admiración por los acontecimientos más trascendentales de la historia patria ("Canto a mi patria", "A Cuba”), así como a sus figuras relevantes ("Carlos Manuel de Céspedes", "A Martí", “Al inmortal Heredia”, "Al invicto caudillo Salvador Cisneros Betancourt”). Presta atención también al acontecimiento político-social más importante del momento en el orden global: la I Guerra Mundial ("A la heroica Bélgica" y "A la indómita Alemania”), tópico tratado además por otros poetas santiagueros como Luis Augusto y Pedro Duany Méndez. Incluye, asimismo, una poesía de orientación religiosa (“Jesucristo"); y en otras como "El carnaval", se advierte la exégesis costumbrista popular.

También de 1917 data el poemario Expansiones, del catalán Santiago Fals. Aplatanado $^{8}$ en la región desde la anterior centuria, Fals había contribuido al desarrollo del movimiento literario local en las publicaciones periódicas 
de finales del siglo XIX e inicios del XX. Expansiones contiene tardíos textos reveladores de su trasnochada filiación romántica ("Ya es tarde"), de la vocación identitaria del discurso poético regional ("Maceo", "La mujer cubana", "La mujer oriental"), o bien de una poesía que combina la delicada nota humorística con tendencia moralizante ("A un mosquito", "La deuda", "Padre escarmentado"), más cercanas al estilo de expresión popular. En esta línea se adscriben, de Arturo J. de Lastre Manduley, Humo azul (1918), discreto y de escasas resonancias en el ámbito neorromántico; y Musa popular, de José Olano, poemario de mayores relieves estéticos en cuanto a temas novedosos abordados: las luchas reivindicadoras por los derechos morales y emancipatorios de la mujer ("La mujer cubana"). Estos tópicos fueron centrales en el debate nacional que justamente en 1918, cuando este volumen ve la luz, cristaliza en la aprobación de la Ley del Divorcio en Cuba. Asimismo, el sentimiento antinjerencista y de frustración nacional, el pesimismo y la marginalización del sector obrero, imprimen a determinadas composiciones un sentido de denuncia. De este modo, Musa popular, hasta donde se ha podido indagar, contiene los primeros gérmenes de la poesía de tendencia social y proletaria en la lírica regional del período ("Al gremio de tabaqueros", "Pobre mi Cuba"). Por otro lado, los textos demostrativos de la admiración del poeta por su ciudad natal y sus paulatinas transformaciones urbanísticas ("El progreso de Santiago"), expresan la proyección identitaria de nuestra poesía local. No están exentos, sin embargo, del hálito pesimista y desesperanzador cuando avizora las problemáticas sociopolíticas que atentan contra el progreso citadino de un Santiago que muestra en sus esplendores y miserias.

Autor de inquietudes literarias muy cercanas a la renovación povedeana, Ghiraldo Jiménez Rivery (1892-1986) publica su única obra lírica en 1919, Selva interior, sugerente título que trasluce un abigarrado mosaico de pasiones, sentimientos y reflexiones individuales del hombre agobiado por la incertidumbre y el desequilibrio emocional. Aunque escrita por un santiaguero que permaneció gran parte de su vida ajeno al contexto intelectual y literario citadino $^{9}$, Selva interior sella la producción lírica de la segunda época republicana.

9 Estudió medicina en La Habana, mantuvo vínculos con el Grupo literario de Manzanillo, colaboró en la revista cultural Orto, de esa región oriental, no así en revistas literarias de Santiago y radicó, posteriormente en Sagua de Tánamo, Holguín, donde ejerció la profesión y otras actividades intelectuales y políticas. 
Obra expresiva de las inquietudes sensoriales e ideológicas de su autor, es también muestra de la angustia de un estado emotivo de visible deterioro, marcado por la inconsistencia y el desequilibrio, la pesadumbre descarnada y su actitud pesimista ante la vida. En síntesis, el sustrato ideotemático de sus composiciones líricas pueden resumirse del siguiente modo: búsqueda de la belleza como ideal estético supremo en todas sus manifestaciones, asumiendo una actitud creadora en el terreno artístico. Esto evidencia la preocupación del vate por el perfeccionismo, la renovación del estilo y la forma en su concepción del verso, atento a los nuevos postulados estéticos (“El arte supremo”, “Cómo es mi lira?”); el ansia de libertad espiritual del sujeto lírico (véase, por ejemplo, “Amplitud”), vencido por el cansancio, la irresolución, el miedo y además, el tratamiento simbólico de la naturaleza en poemas como "El gran río" y "La montaña maldita".

A lo anterior se añade la temática amorosa en composiciones centradas en la angustia por la pérdida de la mujer amada, en el dolor del yo poético que ha experimentado demoledoras experiencias personales. En esos textos, la belleza femenina, espiritual y carnal, es evocada con melancolía y tristeza mística ("La esperada", "El gozo de las paralelas", "Tu recuerdo"). Asimismo, la preocupación del hombre por su destino, ajeno a estimativas metafísicas; el ansia de experimentación de nuevas sensaciones, incluidos el vicio, los ambientes lúgubres y nocturnos, en poemas de enfática bipolaridad simbólica, constituyen otras facetas del esteticismo renovador en la obra de Jiménez Rivery. A pesar de su abigarrado aliento pesimista, Selva interior, notable ejercicio poético de circunstancias, a diferencia de los textos povedeanos, deja entreabierta la posibilidad de vislumbrar una alborada de esperanza y crecimiento espiritual en el discurrir del hombre por la vida.

En 1920 aparece Consagración Eterna. Poesías y prosas, de Clavijo Tisseur, dedicado a Emilio Bacardí Moreau y Elvira Cape. Este, su segundo texto poético, no escapa a las influencias de la tendencia postmodernista. Se aprecia una expresión lírica encaminada hacia la madurez, de personalidad más definida en composiciones que legitiman la autoconfianza del autor en el difícil proceso de creación literaria ("Yo", "Clavijo Tisseur", "Sed de espacio", "No sé quien soy, pero sé...”). También se lee aquí la glorificación de nuestros símbolos nacionales y locales: Antonio Maceo, José Martí, Guillermo Moncada, la Patria ("Símbolos heroicos", "Ramo de lirios"). Por otra parte, Clavijo Tisseur dedica gran parte de las secciones de su nueva obra a las poesías de contenido amoroso, en las cuales el tríptico musa-poeta-mujer se integra en una policromía laudatoria, evocadora de la inspiración y el deseo 
obcecado de aspirar a la perfección composicional del verso ("Musa lírica; "Ansiedades de luz"). Textos como "Amor indescifrable" y "En el calvario de mi madre", clasificados en la vertiente amoroso-intimista, se destacan por su marcado matiz autobiográfico. De menor presencia, aunque no por ello debe dejar de mencionarse, aparecen composiciones de tema político-social relacionadas con la I Guerra Mundial ("El fantasma del mundo", "La fiera de Berlín", "Amor o guerra"). Se observa también la religiosidad que apela a los designios divinos, como fuente generadora de inspiración, en poemas como "Blasón olímpico", "Aspiración cristiana", "Jesús...! Maestro...!", "Hacia Dios", "Las palabras del loco". La reflexión filosófica, de acentuado matiz místico-espiritualista, matiza el mensaje ideoestético de poemas como "Visión pagana" y "Clave de vida", en los cuales son notorias las referencias simbólicas a la fe católica y a las prácticas masónicas, ambas profesadas por el autor durante su vida.

En 1921, Luis Augusto Méndez (1888-1970), poeta de inquietudes políticas de izquierda, publica Del vergel interior, en el que manifiesta una proyección latinoamericanista y social, así como su preocupación por los destinos de la patria y el continente, amenazados por el intervencionismo norteamericano. "El porvenir de la América Latina", "El minero", "Soy universal" y "Renovación" señalan la influencia del más avanzado ideario progresista de los poetas locales, conscientes de la necesaria emancipación de los pueblos oprimidos y de la lucha de clases como medio viable para alcanzar los ideales de justicia, igualdad y el bienestar social anhelado. La organicidad del texto en secciones permite discernir un equilibrio en los poemas, en consonancia con las bases ideotemáticas de la lírica santiaguera del momento: el intimismo-amoroso, que centra a la mujer como motivo recurrente de inspiración ("Tu retrato", "De la ausencia", "Mensaje"), trasunta una espiritualidad mística, de fina sensibilidad; los conflictos existenciales de la humanidad y el tema de la Gran Guerra expresan el desconcierto del sujeto lírico en tonos de denuncia y rebeldía ("Bélgica", "La caída del Kaiser", “¡Regeneración o muerte!”, "La visión del gran siglo”). Complementan este volumen otros poemas de sabor filosófico y acentuada urdimbre romántica ("Mis amores", "De mi vida", "A solas", "Alma cuéntame", "Mi amor", "Entre cadenas") y composiciones alusivas a acontecimientos y personajes históricos de alcance nacional e hispanoamericano como Bolívar, Colón, José de Diego, Heredia, Maceo, en "El porvenir de América Latina”, "Salutación”, "Canto a Heredia" e "Invocación", respectivamente. 
En este mismo año se editan Cantos de amor y olvido, de Enrique Cazade (1891-?), poeta neorromántico que ya venía desplegando su labor literaria en las páginas de "Domingos de El Cubano Libre". Del malogrado Luis Vázquez de Cuberos aparece La pampa y otras poesías (1922); los poemarios Desprendimientos (1922), de José Stevens Romero y Lira en bruto (192?) ${ }^{10}$, de Enrique Caignet Salomón (1892-1976), presentan coincidencias temáticas en cuanto al tratamiento de la poesía amatoria, de preocupación y crítica social, así como de tema histórico.

De mayor novedad, resultan las Semblanzas orientales del mexicanosantiaguero Wifrido Martínez Chablé (1876-?), publicados en 4 tomos entre 1922 y 1928. Natural de Tabasco, en la tierra azteca, Martínez Chablé emigró a la capital oriental probablemente a finales de la segunda década, donde se incorporó a las labores periodísticas como administrador del rotativo local $E l$ Sol, fundado por Max Henríquez Ureña. Los textos del mexicano sobresalen por su singular caracterización de los emblemáticos personajes retratados en sus composiciones, todos (o casi todos) figuras destacadas del mundo intelectual, cultural, político, económico y social de la ciudad de Santiago de Cuba y del país. Emilio Bacardí, Rodolfo Hernández Giro, Jorge Mañach, Arturo Clavijo Tisseur, Carlos Forment, Antonio Bravo Correoso, Armando Leyva, Max Henríquez Ureña, Ducazcal y muchos otros entre las centenares de personalidades que se mencionan, aparecen representados con vivacidad y estilo ameno, en tanto imprime a sus sonetos ingenio y vis cómica, de marcado sabor popular. Son textos concebidos, al decir de su prologuista Francisco Martínez Anaya, a "vuelapluma" (VII), probablemente en el deambular cotidiano del poeta por la ciudad, de la cual supo captar con maestría sus tipos y costumbres. Uno de los aciertos de estos volúmenes lo constituye, sin dudas, las caricaturas realizadas por las firmas más prestigiosas de la época, encargos del propio autor para acompañar las referencias etopéyicas y prosopográficas de los personajes descritos en sus sonetos. Dibujos de

10 No ha sido posible determinar con exactitud la fecha de aparición de este último, dentro de la década del 20. El ejemplar del poemario no lo consigna. Por otra parte, León Estrada, en su semblanza sobre el autor en su imprescindible Santiago literario (165) sostiene que la investigación efectuada por Edgardo Lora Crespo asegura que este texto poético probablemente no es de la autoría de Enrique Caignet sino de su hermano, el más conocido y afamado Félix Benjamín Caignet. Esta aseveración no ha podido ser comprobada, por lo que a los efectos de este trabajo investigativo se asume aquí al primero como autor de la obra, según indica el poemario impreso en su edición príncipe. 
Conrado Massaguer, Carlos Ramírez Guerra, de Hernández Giro, Eduardo Abril Lamarque, Ernesto Medrano, Martínez Florit y otros, incrementan el valor artístico-literario de Semblanzas orientales.

\section{EPÍLOGO INCONCLUSO DE UN ESTUDIO PRELIMINAR}

A modo de conclusiones, puede afirmarse que el panorama de la lírica en Santiago de Cuba en la etapa republicana comprendida entre 1902-1923, experimentó un despertar significativo, marcado por el predominio de las estéticas que -por estos años-, centraron el horizonte poético regional y nacional: el neorromanticismo, heredado de la praxis escritural del fenecido lapso decimonónico, y el postmodernismo, que orientó de manera prolífica la ruptura con los moldes tradicionales impuestos al género.

Con la guía tutelar de José Manuel Poveda, autor de Versos precursores, surge una nueva generación de poetas agrupados en el emblemático círculo literario del Palo Hueco, denominado "Cenáculo", los cuales aportaron las directrices orientadoras del cambio, influidas también por el espíritu renovador de Regino E. Botti en Guantánamo, con su Arabescos mentales (1913), el primer poemario símbolo de la necesaria transformación lírica a la que aspiraban. El tratamiento de tópicos diversos en la concepción poética de los textos escritos por autores santiagueros evidencia resultados cualitativos notables si se comparan con la producción lírica anterior a esta fecha. No obstante, debe reconocerse que el romanticismo coexistió de manera preponderante con la exégesis postmodernista que implicó una ruptura con las tradicionales concepciones estéticas del hecho lírico en la gran mayoría de las obras analizadas. Al mismo tiempo, es palpable una praxis que todavía muestra una resistencia al cambio, aunque una y otra estéticas perfilaron las bases para el despegue definitivo del género, a partir de 1923 y hasta 1958, etapa en la cual la exégesis vanguardista aportará nuevos derroteros e incentivos, tanto en el contenido como en la forma del discurso lírico regional. Si bien estas coordenadas preliminares pretenden, en sentido general, sentar las bases para el necesario e impostergable ejercicio de rescate, valoración y reescritura de la memoria historiográfica literaria en la ciudad de Santiago de Cuba, en particular, de su género lírico, es importante subrayar la importancia de realizar estudios in profundo sobre las características discursivas de los autores aquí mencionados y sus obras, pues a excepción del caso de Poveda, 
se trata de autores escasamente conocidos hasta el presente por los estudiosos de la literatura cubana.

\section{BIBLIOGRAFÍA}

Barros, Bernardo G.: "Prólogo". Ritmos panteístas. La Habana: El Siglo XX, 1918. p. 11. Caignet Salomón, Enrique. Lira en bruto. Santiago de Cuba: José R. Pascual, impresor (s.f.). Canseco Aparicio, Margarita et al. Nocturnal. Poesía escogida de Rafael Pullés y Palacios. Santiago de Cuba: Ediciones Santiago, 2010.

Cazade, Enrique. Canto de amor y de olvido. Manzanillo: El Arte, 1921.

Clavijo Tisseur, Arturo. Albores y penumbras. Poesías. Santiago de Cuba: La Moderna Poesía, 1917.

Consagración eterna. Poesías y prosas. Santiago de Cuba: La Moderna Poesía, 1920.

Estrada, León. Santiago literario. Santiago de Cuba: Editorial Oriente-Fundación Caguayo, 2013. Fals, Santiago. Expansiones. Santiago de Cuba: Arroyo Hermanos, 1912.

Guerrero, Pascual. Almas ausentes. Santiago de Cuba: Arroyo Hermanos, 1912. En silencio. Santiago de Cuba (s.e.), 1915. Ritmos panteístas. Poesías. La Habana: El Siglo XX, 1918.

Henríquez Ureña, Max. Fosforescencias, Santiago de Cuba: Archipiélago, 1930. Hernández Miyares, Enrique. Tú y mi patria, Habana: Editorial Cuba, 1936.

Instituto de Literatura y Lingüística “José Antonio Portuondo Valdor”. Diccionario de Literatura Cubana. 2 t. La Habana: Editorial Letras Cubanas, 1980-1984.

Historia de la Literatura Cubana. Tomo 1. La Colonia. La Habana: Editorial Letras Cubanas, 2005.

Jiménez Rivery, Ghiraldo. La selva interior, Poesía. Manzanillo: El Arte, 1919.

López Lemus, Virgilio. El siglo entero. Santiago de Cuba: Editorial Oriente, 2012.

Manduley Alcina, Arturo de J. Humo azul. Poesías. Prólogo de Max Henríquez Ureña, Santiago de Cuba: La Moderna Poesía, 1918.

Martínez Anaya, Francisco. "Prólogo". Semblanzas orientales. T-1. Santiago de Cuba, 1922. I-IX.

Martínez Chablé, Wifrido. Semblanzas orientales. T-1. Santiago de Cuba, 1922.

Méndez, Luis Augusto. Del Vergel interior. Poesías, Manzanillo: El Arte, Cuba, 1921.

Navarro Riera, Joaquín. "Obertura en prosa”. Prólogo a Almas ausentes. Santiago de Cuba: José Arroyo Ramos, 1912. 9-10.

Olano, José. Musa popular. Colección de versos. Santiago de Cuba: La Moderna Poesía, 1918.

Poveda y Calderín, José Manuel. Versos precursores. Facsimilar de la edición príncipe. Manzanillo: Ediciones Orto, 2010.

Poemetos de Alma Rubens, Santiago de Cuba: Editorial Oriente, 2004. 
Rocasolano, Alberto (comp.). Órbita de José Manuel Poveda. La Habana: UNEAC, 1975. Stevens, Romero, José. Desprendimientos. Santiago de Cuba: 1922.

Vázquez de Cuberos, Luis. La pampa y otras poesías. Santiago de Cuba: Editorial Oriente, 1922. 